\title{
Development of Manual Orange (Citrus sinensis) Fruit Harvesting System
}

\author{
P.R. Sabale, R. D. Nalawade*, T.B. Bhosale and S.S. Meena \\ CTAE, MPUAT, Udaipur- 313001, Rajasthan, India \\ *Corresponding author
}

\section{A B S T R A C T}

\begin{tabular}{|l|}
\hline K e y w o r d s \\
Orange harvester, \\
$\begin{array}{l}\text { Micro-camera, } \\
\text { Harvest rate, Fruit } \\
\text { damage, } \\
\text { Musculoskeletal } \\
\text { stress. }\end{array}$ \\
\hline Article Info \\
\hline $\begin{array}{l}\text { Accepted: } \\
\text { 26 September } 2017 \\
\text { Available Online: } \\
\text { 10 November } 2017\end{array}$ \\
\hline
\end{tabular}

\section{Keywords}

Harvest rate, Fruit

damage,

10 November 2017
India is one of the largest producers of orange in the world. Among the various operations followed by the producers while cultivation of orange, harvesting is the most critical in terms of possible damage to the fruits and musculoskeletal stress on the worker. This research work was carried out to develop the ergonomically feasible manual orange fruit harvesting system. The developed system consists of the aluminum tripod adjustable as per the operator's height and the whole harvester assembly mounted on the tripod. The micro camera and display arrangement reduce musculoskeletal stress on the operator. The performance of the improved system evaluated in terms of fruit selection, harvest rate, fruit damage and field performance by field tests and compared with traditional harvesting methods. The maximum harvest rate ranged from 49.26 to $64.12 \mathrm{~kg} / \mathrm{h}$ and 37.12 to 45.70 $\mathrm{kg} / \mathrm{h}$ for the harvesting of orange fruits by the traditional and improved method, respectively. The average damage to fruits in traditional method observed 14 percent and it was almost no fruit damage in improved method. The improved harvesting system found better than traditional methods and reduces musculoskeletal stress on the operator.

\section{Introduction}

With a total production of 11.65 Million tonnes, India is the 4th largest producer of citrus in the world (NBH, 2015). In India, citrus ranks second in the area, sharing 15 percent of the total area under fruit crops. Citrus is of high importance in the horticultural industry nowadays and a substantial source of income for the producers. Under citrus group, mandarins are the important, occupying 30 percent of the total area under citrus followed by limes (NBH, 2015).

Among the various operations followed by the producers while cultivation of orange, harvesting is the most critical in terms of cost of operation and possible damage to the fruits.
Harvesting of orange is labor intensive operation and may involve $35-45 \%$ of total production cost (Sanders, 2005). Most of the Indian farmers still practicing conventional hand-picking methods for harvesting. However, conventional methods are inefficient and more importantly results in deterioration of fruit quality and fruit damage. It is also seen that Hand-picking of fruits poses a risk on both the quality of harvested fruits and disorders of the musculoskeletal system of workers during the harvest (Mlotek, 2015). A high stress on the human motoric system is observed when the picker is holding a container of fruit (basket, bucket) with one hand and picking fruit with the other hand (Mlotek, 2015). Moreover, considerable neck 
pain has been reported during harvesting of fruits situated at the upper periphery of the tree. Therefore, the worker cannot harvest continuously (Mlotek, 2015). Also, there are injuries to workers due to falling from trees, ladder and unbalance of a stick.

Mechanical harvesters such as limb shaker, canopy shaker, trunk shaker, air blast are designed for mass removal of orange fruit. Mechanical harvesters provide higher harvesting rate over traditional hand-picking harvesting methods. However mechanical harvesters have some issues associated with them such as fruit quality, size selection and damage to the fruit tree (Lee, 2011).

Physical damage caused by mechanical harvesting of fruits not only halts the physical appearance of orange fruit but also degrade the fruit quality. By keeping above points into consideration, research work was formulated to develop ergonomically feasible orange fruit harvester for the small orchard.

\section{Materials and Methods}

\section{Design of harvester}

The dimensions of orange fruit harvester were selected based on the Physical properties of orange fruit, i.e., fruit dimensions, maximum allowable compressive force.

Orange tree characteristics, i.e., Plant height, plant density, tree canopy.

Anthropometric characteristics of farm workers, i.e., Grip diameter, shoulder grip length, Maximum grip length, Grip span.

To decide the grip of handle following dimensions were selected from the anthropometric database of farm workers of the Rajasthan state: available at AICRP on ESA, Udaipur center shown in table 1.

\section{Fabrication of system components}

\section{Extension pipe (telescopic pipe)}

It is long hollow stainless steel pipe fitted on a tripod. Extension or telescopic pipe was having an adjustable length to have easy reach to the fruit. The two locking mechanisms were provided to extend or shorten the telescopic pipe as per requirement. The length of the telescopic pipe depends on the maximum tree height. It can rotate in any direction (around 360 degrees) to reach any fruit location.

\section{Cutting mechanism}

The Falcon pruning secateurs used as a cutting mechanism as shown in plate. 1. It fitted on one of the ends of the extension pipe. It consists of scissor having one of the blades was fixed and other was move to have a cut on the pinnacle of fruit. The fruit-guider was provided to guide the fruit within cutting zone. Hence, the cutting efficiency of the cutter increased.

\section{Fruit collection bag}

Fruit collection bag fitted at the end of extension pipe in such way that the fruit cut by cutting mechanism will fall in the bag. The maximum capacity of fruit collecting bag was decided based on the ability of extension pipe to sustain the load of a bag filled with fruits with minimum possible bending.

\section{Micro camera and display}

The micro camera was fitted just behind the cutting mechanism to locate the fruits as shown in plate 2 . The micro camera streams the real-time video on display mounted on supporting assembly of the telescopic tripod. The micro camera can establish a wireless connection with display through Wifi, so that 
eliminates the need for connection through wiring. The display fitted on supporting beam in such way that its height can adjust according to the height of operator. The MS cover is also provided to protect the display from open atmosphere and to shade the display for better visibility of operator.

\section{Supporting Pipe}

The supporting pipe made up of Stainless steel material mounted on the tripod. The diameter of supporting pipe was kept slightly greater than the extension pipe for free movement. The purpose of supporting pipe was support as well as to prevent the extension pipe from bending.

\section{Handle}

The handle is provided to operate the cutting mechanism. It consists of steel cable having one end is connected to the cutting mechanism, and another end connected to the free end of extension pipe. The cutting mechanism operated by pulling cable in a downward direction when the fruit is in cutting zone. Cable takes its original position due to the action of spring fitted on the cutting mechanism.

\section{Supporting assembly}

The supporting assembly consists of trust bearing for $360^{\circ}$ rotation of beam, provision for locking of extension pipe to a suitable position, Provision for display mounting, etc. Plate 3 shows the supporting assembly of the harvester.

\section{Telescopic tripod}

The whole harvesting assembly mounted on the telescopic tripod. It is rigid enough to sustain a load of all parts of harvester without any deformation. The height of telescopic tripod can adjust according to the requirement.

\section{Operation of harvester}

The harvester was developed to cut orange fruits pedicle by using scissor action. The operation of the harvester is shown in plate 4 . The harvester components assembled and checked for any loose parts if any they tightened immediately. The harvester placed on fairly leveled ground between groups of four trees (spacing not more than $5 \times 5 \mathrm{~m}$ ) in such way that it has access to all of them. The camera connected to the display through a wireless connection and checked for any error.

In operation, the operator holds the cable in one hand and another hand hols free end of extension pipe as shown in the plate. The camera streams the real-time video on display; operator locates the fruit with the help of display.

As soon as fruit comes in cutting zone of the cutting mechanism, cutting mechanism operated by pulling cable in a downward direction. The fruit cut by cutting mechanisms fallen into collection bag provided just below it.

\section{Results and Discussion}

There are several important aspects of the successful operation of the orange harvesting system. The performance of the harvesting system about each aspect given below

\section{Fruit selection}

With the help of micro-camera display arrangement, better fruit selection was possible. The micro camera sends better quality pictures on the display that helps the operator to identify matured fruits easily. 


\section{Harvest rate}

The output capacity or harvesting efficiency of fruit is mostly affected by the number of fruits present on the tree. Harvest rate obtained during prototype trial presented in table 1. The maximum harvest rate ranging from 49.26 to $64.12 \mathrm{~kg} / \mathrm{h}$ and 37.12 to 45.70 $\mathrm{kg} / \mathrm{h}$ for the harvesting of orange fruits by traditional and improved technique, respectively. The harvest rate is more in traditional method compared to the improved method because of hand picking and sticks striking methods used for harvesting.

\section{Fruit damage rate}

Fruit damage during harvesting is the key point for the evaluation of harvesting system. Table 2 indicates the fruit damage during harvesting by traditional and improved harvesting system. It indicated that traditional method involves more amount fruit damage compared to an improved method which has no fruit damage.

It has seen that traditional method involves $14 \%$ fruit damage while improved method does not involve any damage to the fruits (Table 3).

The reason behind the damage during the traditional harvesting because it involves striking by stick causes severe damage to the fruit. There no provision for catching of fruit causes free falling of fruit directly on the ground. Improved harvesting system has a fruit collection bag which catches the harvested fruits without allowing them to fall from much greater height results in no damage to the fruits.

Table.1 Anthropometric characteristics of farm workers for Rajasthan state

\begin{tabular}{|l|c|c|c|c|c|c|}
\hline \multicolumn{1}{|c|}{ Parameters } & Min & Max & $\mathbf{5}^{\text {th }}$ & $\mathbf{5 0}^{\text {th }}$ & $\mathbf{9 5}^{\text {th }}$ & SD \\
\hline Grip diameter (inside) $(\mathrm{cm})$ & 4.20 & 6.97 & 4.50 & 5.28 & 6.18 & 0.51 \\
\hline Shoulder grip length $(\mathrm{cm})$ & 52.00 & 84.26 & 58.20 & 65.27 & 76.41 & 5.36 \\
\hline Maximum grip length $(\mathrm{cm})$ & 7.20 & 15.70 & 8.14 & 9.70 & 12.64 & 1.38 \\
\hline Grip span (cm) & 2.79 & 11.68 & 5.30 & 7.60 & 10.01 & 1.39 \\
\hline
\end{tabular}

Table.2 Harvest rate of traditional and improved harvesting system

\begin{tabular}{|c|c|c|}
\hline \multirow{2}{*}{ Shift No. } & \multicolumn{2}{|c|}{ Harvest Rate, kg/h } \\
\cline { 2 - 3 } & Traditional harvesting method & Improved harvesting System \\
\hline 1 & 62.21 & 41.20 \\
\hline 2 & 49.26 & 37.12 \\
\hline 3 & 53.84 & 38.65 \\
\hline 4 & 50.23 & 44.37 \\
\hline 5 & 58.14 & 42.94 \\
\hline 6 & 52.18 & 43.79 \\
\hline 7 & 62.89 & 42.26 \\
\hline 8 & 63.66 & 45.70 \\
\hline 9 & 56.30 & 44.92 \\
\hline 10 & 64.12 & 43.85 \\
\hline Avg. & $\mathbf{5 7 . 2 8}$ & $\mathbf{4 2 . 4 8}$ \\
\hline
\end{tabular}


Table.3 Fruit damage comparison between traditional and improved method

\begin{tabular}{|c|c|c|c|c|c|c|}
\hline \multirow{2}{*}{$\begin{array}{c}\text { Shift } \\
\text { No }\end{array}$} & \multicolumn{2}{|c|}{ Traditional Harvesting Method } & \multicolumn{2}{c|}{ Improved harvesting system } \\
\cline { 2 - 7 } & $\begin{array}{c}\text { Harvested } \\
\text { fruit (kg/hr) }\end{array}$ & $\begin{array}{c}\text { Damaged } \\
\text { fruit } \\
\text { (kg/hr) }\end{array}$ & $\begin{array}{c}\text { \% of Fruit } \\
\text { Damaged }\end{array}$ & $\begin{array}{c}\text { Harvested } \\
\text { fruit (kg) }\end{array}$ & $\begin{array}{c}\text { Damage } \\
\text { fruit (kg) }\end{array}$ & $\begin{array}{c}\text { \% of Fruit } \\
\text { Damaged }\end{array}$ \\
\hline $\mathbf{1}$ & 62.21 & 8.70 & 14 & 41.20 & 0 & 0 \\
\hline $\mathbf{2}$ & 49.26 & 7.88 & 16 & 37.12 & 0 & 0 \\
\hline $\mathbf{3}$ & 53.84 & 7.80 & 14.5 & 38.65 & 0 & 0 \\
\hline $\mathbf{4}$ & 50.23 & 6.52 & 13 & 44.37 & 0 & 0 \\
\hline $\mathbf{5}$ & 58.14 & 8.13 & 14 & 42.94 & 0 & 0 \\
\hline $\mathbf{6}$ & 52.18 & 4.17 & 08 & 43.79 & 0 & 0 \\
\hline $\mathbf{7}$ & 62.89 & 8.80 & 14 & 42.26 & 0 & 0 \\
\hline $\mathbf{8}$ & 63.66 & 8.59 & 13.5 & 45.70 & 0 & 0 \\
\hline $\mathbf{9}$ & 56.30 & 10.13 & 18 & 44.92 & 0 & 0 \\
\hline $\mathbf{1 0}$ & 64.12 & 9.61 & 15 & 43.85 & 0 & 0 \\
\hline Avg. & $\mathbf{5 7 . 2 8}$ & $\mathbf{8 . 0 0}$ & $\mathbf{1 4}$ & $\mathbf{4 2 . 4 8}$ & $\mathbf{0}$ & $\mathbf{0}$ \\
\hline
\end{tabular}

Table.4 Field performance comparison between traditional and improved harvesting system

\begin{tabular}{|c|c|c|c|c|c|c|}
\hline \multirow{2}{*}{$\begin{array}{l}\text { Tree } \\
\text { No. }\end{array}$} & $\begin{array}{c}\text { Traditional harvesting method } \\
\text { No. of } \\
\text { position } \\
\text { per tree }\end{array}$ & $\begin{array}{c}\text { No. of fruit } \\
\text { detached } \\
\text { per position }\end{array}$ & $\begin{array}{c}\text { Time } \\
\text { required for } \\
\text { shifting per } \\
\text { position }\end{array}$ & $\begin{array}{c}\text { No. of } \\
\text { position } \\
\text { per tree }\end{array}$ & $\begin{array}{c}\text { No. of fruit } \\
\text { detached per } \\
\text { position }\end{array}$ & $\begin{array}{c}\text { Time } \\
\text { required for } \\
\text { shifting per } \\
\text { position }\end{array}$ \\
\hline $\mathrm{T}_{1}$ & 6 & 30 & $1 \mathrm{~min}$ & 4 & 95 & $3 \mathrm{~min}$ \\
\hline $\mathrm{T}_{2}$ & 5 & 35 & $1.5 \mathrm{~min}$ & 4 & 85 & $3.2 \mathrm{~min}$ \\
\hline $\mathrm{T}_{3}$ & 7 & 25 & $1.2 \mathrm{~min}$ & 4 & 105 & $3.4 \mathrm{~min}$ \\
\hline $\mathrm{T}_{4}$ & 6 & 35 & $1.4 \mathrm{~min}$ & 4 & 90 & $3.1 \mathrm{~min}$ \\
\hline $\mathrm{T}_{5}$ & 7 & 30 & $1.5 \mathrm{~min}$ & 4 & 110 & $3.5 \mathrm{~min}$ \\
\hline Avg. & $\mathbf{6}$ & $\mathbf{3 1}$ & $\mathbf{1 . 3 2 m i n}$ & $\mathbf{4}$ & $\mathbf{9 7}$ & $\mathbf{3 . 2 4 m i n}$ \\
\hline
\end{tabular}

Plate.1 Cutting mechanism

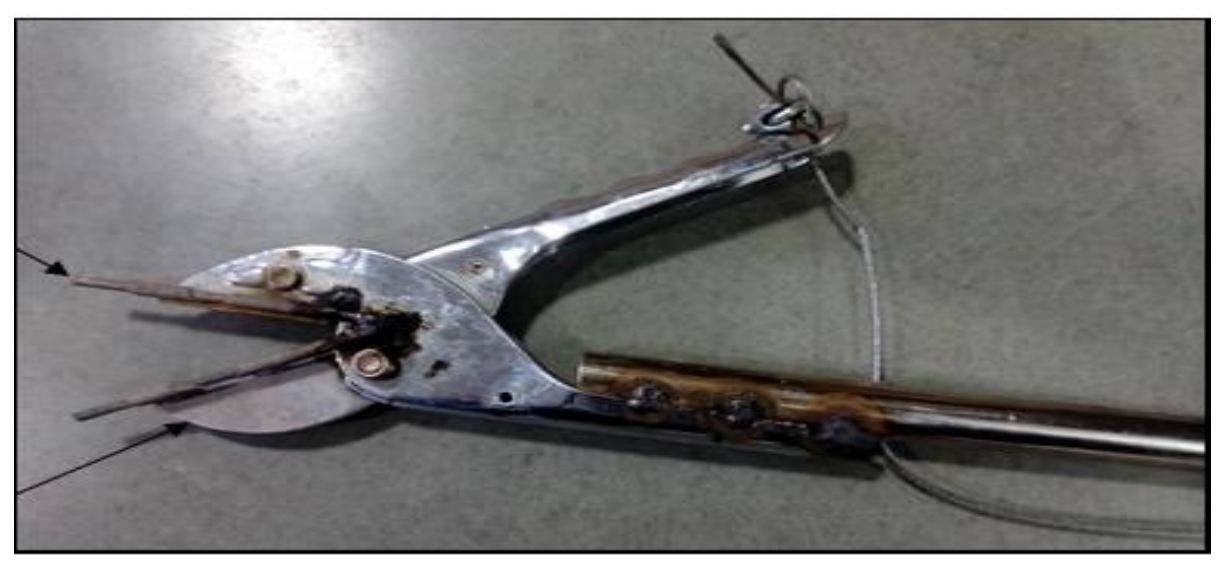


Plate.2 Micro camera

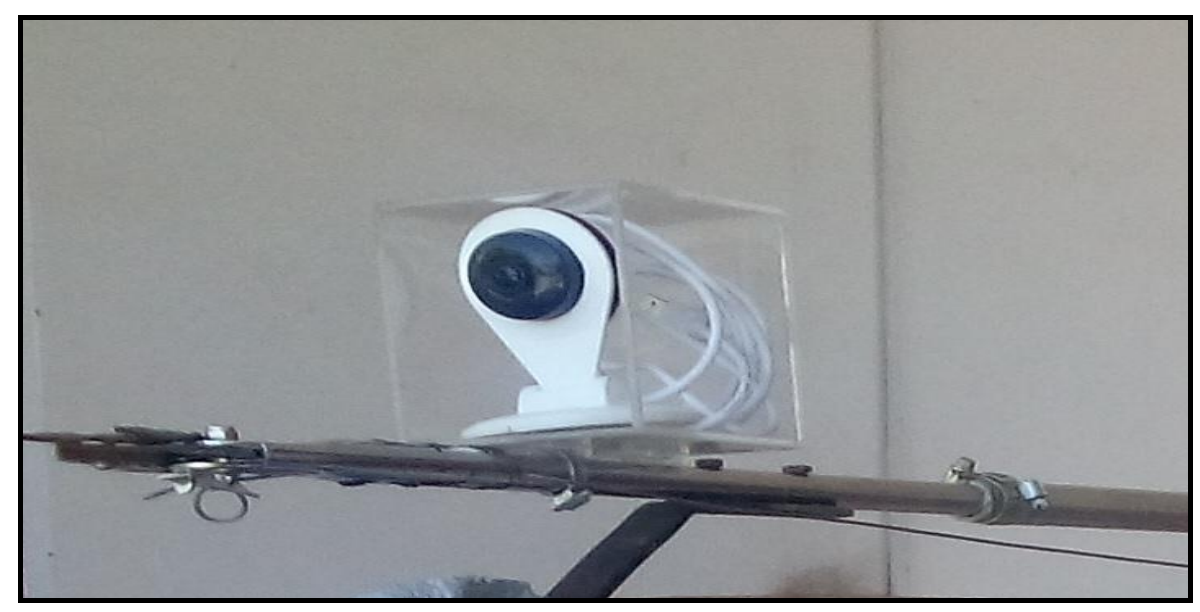

Plate.3 Supporting assembly

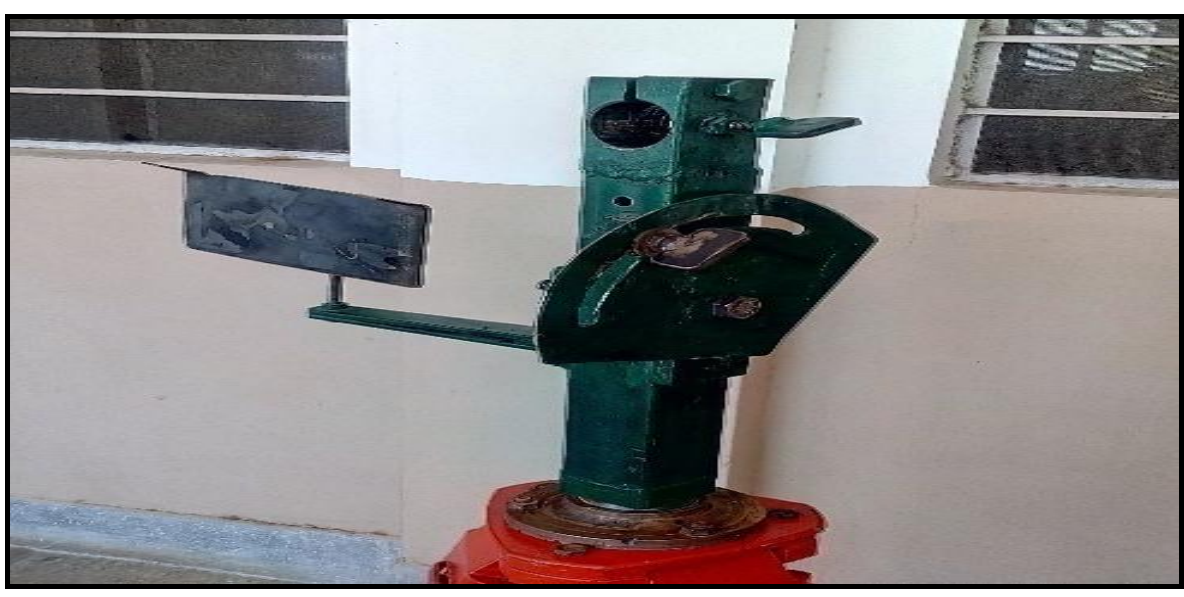

Plate.4 Orange harvester in operation

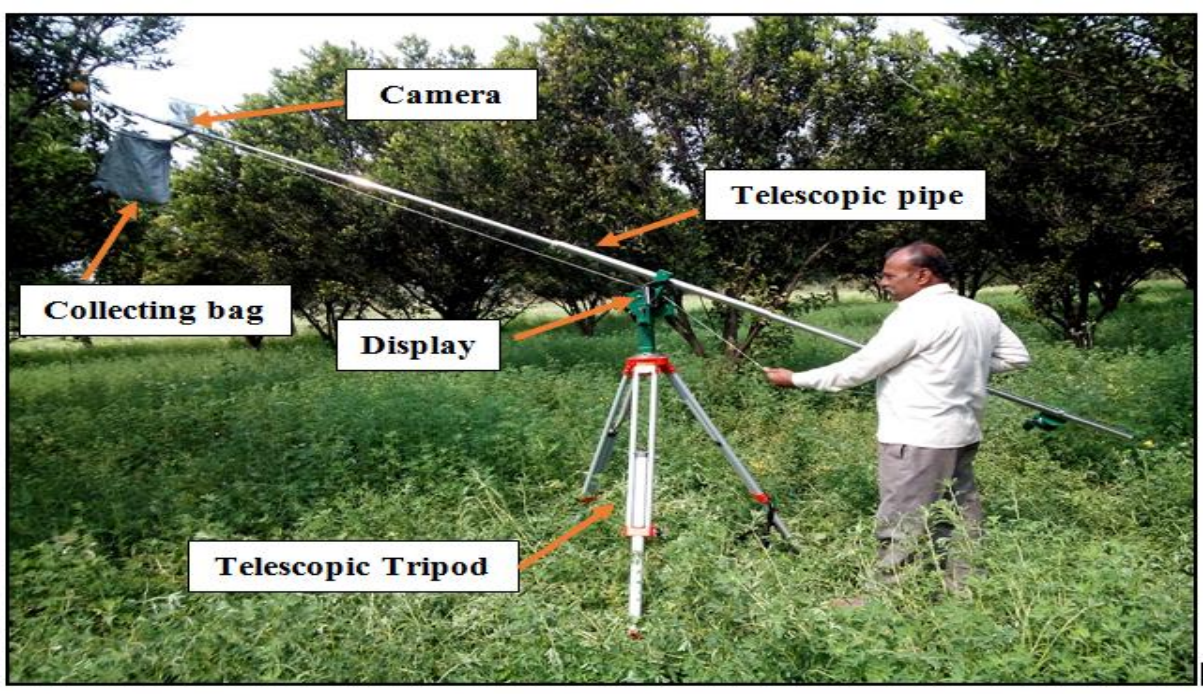




\section{Field performance}

The field performance of the developed method and traditional method was evaluated in the different field by selecting group five adjacent trees randomly. The field performance was evaluated in terms of three parameters vise number of position per tree, number of fruit detached per position and time required for shifting per position. These parameters were evaluated and compared between traditional and improved method (Table 4).

\section{The number of position per tree}

The maximum numbers of positions per tree in the traditional method were seven and in improved method were four, because the improved method has better reach than traditional method hence requires fewer shiftings.

\section{The number of fruit detached per position}

In the traditional method, the average number of fruits detached per position was 31 , and in an improved method it was 97 .

\section{The time required for shifting per position}

The time required for shifting per position in the improved method was $3.24 \mathrm{~min}$ and 1.32 min for the traditional method. The time required for shifting of improved harvesting system was more because balancing of tripod takes time. The research efforts are carried out to develop harvesting system for small orange orchards. It was seen that improved system is easy to assemble and no skilled workforce was required to operate the harvesting system. The shifting time for the system was higher, but it was justified by better ability to cover maximum fruit trees from a single position. The harvest rate was observed lower compared to the traditional harvesting method, but the traditional method resulted in more fruit damage while improved method has no fruit damage. The better selection of matured fruits was possible with the help of micro-camera, display arrangement. As the whole system assembly mounted on telescopic tripod, no load is carried by the operator thus reduces

\section{References}

Li, P., Lee, S.H. and Hsu, H.Y., 2011. Review on fruit harvesting method for potential use of automatic fruit harvesting systems. Procedia Engineering, 23, pp.351-366.

Młotek, M., Kuta, Ł., Stopa, R. and Komarnicki, P., 2015. The effect of manual harvesting of fruit on the health of workers and the quality of the obtained produce. Procedia Manufacturing, 3, pp.1712-1719.

NHB. 2015. Area and Production Statistics. Retrieved Aug 4, 2017, from National Horticulture Board. http://nhb.gov.in /area\%20_production.html

Sanders, K.F., 2005. Orange harvesting systems review.

Biosystems Engineering, 90(2), pp.115-125.

\section{How to cite this article:}

Sabale, P.R., R.D. Nalawade, T.B. Bhosale and Meena, S.S. 2017. Development of Manual Orange (Citrus sinensis) Fruit Harvesting System. Int.J.Curr.Microbiol.App.Sci. 6(11): 34273433. doi: https://doi.org/10.20546/ijcmas.2017.611.403 